\title{
Complementary and Alternative Medicine, When Rigorous, can be Science
}

\author{
Edwin L. Cooper \\ Laboratory of Comparative Neuroimmunology, Department of Neurobiology, and David Geffen School of Medicine at \\ UCLA, University of California, Los Angeles, CA, USA
}

\section{Early Beginnings in China}

In October 2003, during the 12th Congress of Oriental Medicine in Taipei, the National Palace Museum organized an enormously pertinent exhibit in Gallery 313 derived largely from the museum's collection of ancient medical texts that includes classics on numerous topics. It is entitled Life is Worth More than Gold: A Special Exhibition of Ancient Medicinal Classics. In the English translation of the Chinese description clues are embedded that pertain to the origins of both Western medicine and the history of complementary and alternative medicine (CAM) as briefly described:

"Disease has always been a great topic of concern in human society. From prayers and spells to the birth of medicine as a rational science, man has been able to develop all sorts of medical treatments to combat against different illnesses and ailments, because, as the Chinese proverb has it, 'life is worth more than a thousand gold pieces.' Towards the end of the Eastern Han (the 3rd century), typhoid was rampant in China, and the fatality rate was extremely high. Chang Chung-ching, with his extensive clinical experience, wrote the Treatise on Cold-Induced Febrile and Miscellaneous Diseases, and thereby established the foundations for 'treatment based on differentiation of symptom-complex' in traditional Chinese medicine. After that, as governments began setting up medical institutions and experiences of private doctors came to be valued, many important medicinal theories, treatments and much pharmaceutical knowledge were gradually organized systematically. Advancements in pharmacology were particularly notable. For example, the Newly-Revised Materia Medica issued by Emperor Kao-tsung of the T'ang dynasty in the 10th year of his reign (659) was the first pharmacological encyclopedia edited and published by the government, and a copy was taken to Japan by Japanese emissaries soon after its completion."

\section{Why launch Evidence-based Complementary and Alternative Medicine (eCAM)?}

With this brief excursion into our history, it is appropriate to mention to those anxious to read our first issue what we are about. Once again a new journal is born, and in the spring when there is an awakening from a winter's sleep, a rejuvenation (reconstruction, renewal, renovation), a renaissance (rebirth, resurgence, revitalization, revival, reawakening). Many will greet this birth with mixed feelings. With numerous journals devoted to CAM and already flourishing, other readers will consider that it is outright nonsense to start yet another journal devoted to the same subject. Still a greater number of CAM practitioners and basic scientists of all types have agreed to serve on the Editorial Board and to support the aims of $e C A M$ and are certain of the real need for this journal. We all share various depths of elation and cautious optimism, partly because we are doing something a bit unique and partly because of having to compete with other journals that are devoted exclusively to CAM, or where the approaches of the authors are such that their manuscripts fit equally well into more established biomedical journals. In contrast to these elusive feelings, we also harbor the committed and strong belief that this new journal, $e C A M$, will flourish by means of imagination, scientific rigor and cooperative enthusiasm. All disciplines have beginnings met with enthusiasm by founders who must be, of necessity, loyalists-essential to protect against the onslaught of skepticism that always seems to occur when a new movement begins. As a developmental immunobiologist, interested in origins and foundations, I am of course steeped in the beginnings of modern immunology. Let us deal in a bit of musing juxtaposing immunology, science and CAM.

\section{Can eCAM Be Scientific? Lessons from Immunology}

According to Burnet (1):

'The first objective in a serious approach to immunology should be to obtain a broad understanding, with a minimum of detail, of how immunology fits into the pattern of biology — of the way in which the immune system evolved, its function and coordination with other body systems, and its development from the embryo onwards. At the same time, such an outline should provide an adequate background for easy application of immunological ideas to the 
detail of practical immunological work in public health, clinical, and veterinary practice.'

Would it be possible to paraphrase this statement in the context of $e C A M$ so that it reads: 'the first objective in a serious approach to complementary and alternative medicine (CAM) should be to obtain a broad understanding, with a minimum of detail, of how CAM fits into the pattern of biology - of the way in which the neuroendocrineimmune system evolved, its function and coordination with other body systems, and its development from the embryo onwards. At the same time, such an outline should provide an adequate background for easy application of CAM ideas to the detail of practical CAM work in public health, clinical and medical practice, and yet not stray far away from the very biology that under girds it. CAM is organismic, inclusive and not exclusive (2-4).

\section{So How do we Define CAM?}

So does any of this fit? Readers may be wondering just what is complementary medicine and what is alternative medicine? Several definitions may be offered based on different points of view and those in turn influenced by professional training, practice and, perhaps, the dictates of funding agencies. The discipline is a heterogeneous subject, to say the least, and it is unlikely that all the adherent disciplines that are sheltered by the umbrella of CAM will carry equal weight or influence or can be subjected to the same rigors of scientific inquiry. Some of these generalizations apply to all disciplines, including those sub-disciplines that fall under the aegis of the immunology umbrella. However, perhaps CAM is ripe for an infusion of empiricism. Modern immunology, like CAM, has its earliest roots in concerns for health and disease, but immunology never seemed to have been branded with the aura that often shrouds CAM. There were always a group of experimentalists and, perforce, the necessity to use animal models with which experimentation could be performed to test hypotheses. (To be clear and current on all aspects of the discipline, written by seasoned pioneers, readers are kindly referred to references $5-15$ for further reading.)

$e C A M$ is a new concept that encompasses a wider and more inclusive medical science provided by online systems, and this more fully integrated concept comprises alternative, complementary and traditional medicine. At the beginning of the new century we recognize the tremendous success that modern medical science has achieved in the diagnosis and treatment of a number of diseases that were regarded as incurable for decades. Direct intervention through technological and molecular means has become possible. We are now recipients of the full benefit of the progress of modern medical sciences, and Western medicines in particular. Notwithstanding, we have also become aware that a comparative number of diseases still remain incurable by Western medicine, and that patients suffer without any hope of effective treatment. With all its successes, modern Western medicine also has limitations such as unbearable side effects, high medical costs, facilities that are not accessible to everyone, ethical problems, etc. Recently, alternative and complementary medicines, together with oriental and traditional medicines, have attracted much attention. This new interest includes aromatherapy and herbal medications, acupuncture, moxibustion, shiatsu and yoga. Often, however, these therapies have not been well defined. Some are simply based on legend or belief, while others are traditionally applied but without scientific evidence.

\section{The Need for eCAM}

The recent excessive commercialization of the health industry has left us puzzled as to what is true and what is false. Misleading information has been flooding into newspapers and magazines, and exaggerated advertisements can be seen everywhere (16-20). Yet among these there are credible accounts. This situation is particularly confusing for patients and doctors who seek remedies for heretofore undefined symptoms. Furthermore, since these treatments have not undergone strict testing, they are not always safe and the same drug may have different effects according to the individual patient and dosage. Complicated considerations are necessary for the application of practices such as those found in Chinese traditional medicine. Quality control is also important for the safe use of natural products. Due to the above difficulties, this realm of medicine has often been shut out of the serious journals of Western medicine. Our eCAM is launched in a desire to ameliorate this situation, by encouraging the publication of original scientific papers based on sound scientific guidelines, but without prejudice against the possible efficacy of these new and ancient treatments.

A new international journal seeks to understand the sources and to encourage rigorous research in this new, yet ancient, world of complementary and alternative medicine. This international, rigorously peer-reviewed, journal seeks to apply scientific rigor to the study of CAM modalities, particularly traditional Asian healing systems. eCAM will emphasize health outcome, while documenting biological mechanisms of action and will be devoted to the advancement of science in the fields of basic research, clinical studies, methodology or scientific theory in diverse areas of biomedical sciences. With a base in Japan, $e C A M$ will be the first true platform for scientists and practitioners in Asia. With Asia as their home, these contributors are familiar with the way many CAM techniques have been practiced for centuries, giving the journal a firm footing in the history and tradition of CAM. As with any truly important research, one must think radically; in other words, return to the radical or root of a question or practice. A greater understanding of thousands of years of history will give us greater access to the root and may well lead to exciting new discoveries. CAM is a worldwide phenomenon and $e C A M$ will seek to be inclusive of new and old work all over the globe. With this same broad view, we will seek to make the journal truly inter-disciplinary with a varied editorial board on which philosophers and historians 
will be engaged in dialogue with biologists of all types and clinicians. It is our hope that the two bases, one in the east and the other in the West, especially at UCLA, will be gathering places for information and that our combined efforts will bridge cultures as well as CAM and modern biomedicine.

\section{The Future and Impact of $e C A M$}

So where are we? We began in China in a historical context, laying a foundation for CAM and Western medicine with the inference that bridges could be built. By linking the scientific basis of CAM with another discipline that too was once fledgling, now free from lack of empiricism, a foundation of hope was laid and the suggestion of animal models and natural products inferred. According to Normile (10), there is a new face to traditional Chinese medicine. Asian governments hope that high-volume screening and rigorous clinical trials will unlock the secrets of ancient herbal remedies-and that the results will pass muster with Western scientists. According to Vickers (21), there appears to be exceptional and growing public enthusiasm for botanical, or 'herbal', medicines, especially amongst cancer patients. This has recently begun to be matched by increasing scientific attention. Quality control of botanicals poses significant challenges: small differences in genetics, soil, temperature, moisture and time of harvesting can lead to significant differences in the concentration of important constituents. Phase I and II methodology is also problematic: botanicals have low toxicity and are unlikely to cause rapid tumor regression. There is currently minimal regulation of botanical medicines.

Turning to products from animals, particularly those from the sea, according to Haefner (22), in recent years marine natural product bioprospecting has yielded a considerable number of drug candidates. Most of these molecules are still in preclinical or early clinical development but some are already on the market, such as cytarabine, or are predicted to be approved soon, such as ET743 (Yondelis). Research into the ecology of marine natural products has shown that many of these compounds function as chemical weapons and have evolved into highly potent inhibitors of physiological processes in the prey, predators or competitors of the marine organisms that use them. Some of the natural products isolated from marine invertebrates have been shown, or are suspected, to be of microbial origin and this is now thought to be the case for the majority of such molecules. Marine microorganisms, whose immense genetic and biochemical diversity is only beginning to be appreciated, look likely to become a rich source of novel chemical entities for the discovery of more effective drugs. Lombrokinase is a product isolated from earthworms and sold on the market as a fibrinolytic agent (23). We must remember that these products are often associated with the immune systems of these creatures and that they evolved millions of years ago-thus their immune systems have been an effective survival strategy (24-30). And if it has worked for them, then humans should harness these as new-wave antibiotics or anticancer molecules, just to offer two biomedical (CAM) applications.

\section{Acknowledgments}

I am especially pleased to express appreciation to Oxford University Press for joining in the launching of $e C A M$. Without the enthusiastic, personal and amicable support of several persons, $e C A M$ would not be a reality. Martin Richardson, at OUP in England has renewed our older productive and smooth collaboration with another journal, Developmental and Comparative Immunology, and one of my books. Toyoshi Onji (Director of Publications), Emiko Okuda (Marketing Executive), Leslie Nelson (Production Editor) and Akiko Tanaka (Assistant Editor) in the Tokyo Office have been tireless and most patient, and have offered all sorts of intellectual and technical solutions to glitches in our quest to get $e C A M$ going. Of course, I could not do this without the loyal and sustained friendship and generosity of our Managing Editor, Professor Nobuo Yamaguchi. Our uninterrupted collaboration goes back to 1977 , my first visit to Japan, and the beginning discussions that led to our organizing the international congress on complementary and alternative medicine, held in Kanazawa, Japan, November 2002; the proceedings are now in press. This seed, so well planted and then nourished by our International Administrator, Patty C. Willis, continued and has provided the long-term roots of $e C A M$. Without her essential infusion of ideas, friendship, easy cross-cultural facility that usually sparkles with laughter, we could not handle with aplomb some of the more unsavory tasks that so often accompany any creative endeavor.

\section{References}

1. Burnet FM. Immunology, Aging and Cancer. San Francisco: W.H. Freeman and Company 1976;62.

2. Cooper EL. (Ed.) Stress, Immunity and Aging. New York, NY: Marcel Dekker, Inc. 1984

3. Cooper EL. Immune system: an overview. In Cooper EL. (ed.) Stress, Immunity and Aging. New York, NY: Marcel Dekker, Inc. 1984:13-26.

4. Cooper EL and Brazier MAB (eds) Developmental Immunology: Clinical Problems and Aging. UCLA Forum in Medical Sciences, Vol. 25. New York, NY: Academic Press 1982.

5. Cooper EL and Yamaguchi N. (eds) Complementary and Alternative Approaches to Biomedicine. Proceedings. New York, NY: Kluwer Publishers 2004; in press.

6. Ernst E. Complementary medicine: a critical appraisal. Oxford, UK: Butterworth-Heinemann 1996.

7. Leibovici L and Haynes RB. Alternative (complementary) medicine: a cuckoo in the nest of empiricist reed warblers. Commentary: A warning to complementary medicine practitioners: get empirical or else. $\mathrm{Br} \mathrm{Med}$ $J$ 1999;319:1629-32.

8. Lewith G, Kenyon J, Lewis P. Complementary medicine: an integrated approach. Oxford General Practice Series. Oxford, UK: Oxford University Press 1996.

9. Lewith GT, Ernst E, Mills S, Fisher P, Monckton J, Reilly D, Peters D, Thomas K. Complementary medicine must be research led and evidence based. Br Med J 2000;320:188.

10. Normile D. The new face of traditional Chinese Medicine. Science 2003;299:188-90. 
11. Penson RT, Castro CM, Seiden MV, Chabner BA, Lynch TJ. Complementary, Alternative, Integrative, or Unconventional Medicine? Oncologist 2001;6:463-73.

12. Vickers AJ. (ed.) Examining complementary medicine. Cheltenham, UK: Stanley Thornes 1998.

13. Vincent C, Furnham A. Complementary medicine: a research perspective. London, UK: Wiley 1997.

14. Woodham A, Peters D. An encyclopaedia of complementary medicine. London, UK: Dorling Kindersley 1997.

15. Zollman C, Vickers A. ABC of complementary medicine, what is complementary medicine? Br Med J 1999;319:693-6.

16. L'Express. Les recettes des nouveaux sorciers du bien-être. November 20-26, 2003;88-96.

17. Newsweek. Arthritis: what it is, why you get it and how to stop the pain. September 3, 2001;38-51.

18. Newsweek. The science of alternative medicine, depression treatments, acupuncture and herbs, natural HRT plus insights from Harvard medical school. December 2, 2002;45-76.

19. Newsweek. God and Health. Is religion good medicine? Why science is starting to believe. November 10, 2003;44-56.

20. Time. You your mind can heal your body. New ways to beat the blues, the link between mental and physical health, is happiness in your genes? Women, men and depression. January 20, 2003;62-126.

21. Vickers A. Botanical medicines for the treatment of cancer: rationale, overview of current data, and methodological considerations for phase I and II trials. Cancer Invest 2002;20:1069-79.
22. Haefner B. Drugs from the deep: marine natural products as drug candidates. Drug Discov Today 2003;8:536-44.

23. Cooper EL, Ru B, Weng N. Earthworms: sources of antimicrobial, and anticancer molecules. In: Cooper EL and Yamaguchi N. (eds) Complementary and Alternative Approaches to Biomedicine. Proceedings. New York, NY: Kluwer Publishers 2004; in press

24. Beck G, Habicht GS, Cooper EL, Marchalonis JJ. (eds) Primordial Immunity, Foundations for the Vertebrate Immune System. New York, NY: New York Academy of Sciences 1994.

25. Beck G, Sugumaran M, Cooper EL. (eds) Phylogenic Perspectives on the Vertebrate Immune System. Adv Exp Med Biol 2001;484:1-383.

26. Cooper EL. Invertebrate immune responses: Cells and Molecular Products. Adv Comp Environ Physiol 1996;23:1-216.

27. Cooper EL, Beschin A, Bilej M. A new model for analyzing antimicrobial peptides with biomedical applications. Amsterdam, the Netherlands: IOS Press 2002.

28. Faisal M, Chiappelli, F Ahmed II, Cooper EL, Weiner H. Neuroimmunologia evolutiva: lo stress da confrontazione sociale nei pesci aggressivi. Neuroscienze 1990;1:42-53.

29. Faisal M, Chiappelli F, Ahmed II, Cooper EL, Weiner H. Social confrontation stress in aggressive fish is associated with an endogenous opioid-mediated suppression of proliferative responses to mitogens and nonspecific cytotoxicity. Brain Behav Immun 1990;3:223-33.

30. Ghoneum M, Sadek IA, Gill,G, Cooper EL. Ascorbic acid suppresses natural killer cell activity in Bufo marinus. Dis Aqua Orgs 1990;9:1-4. 


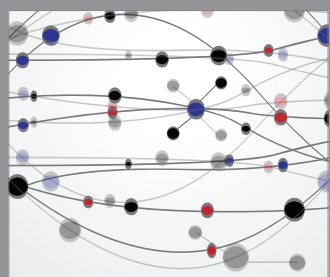

The Scientific World Journal
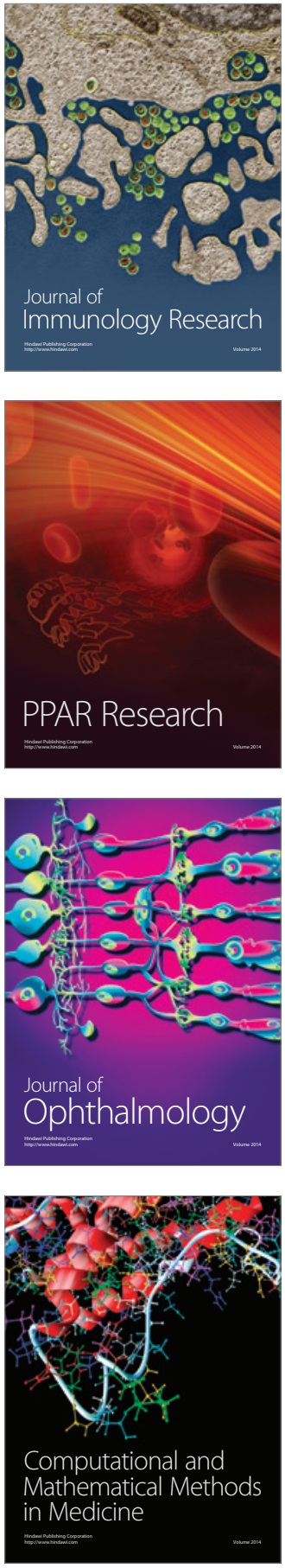

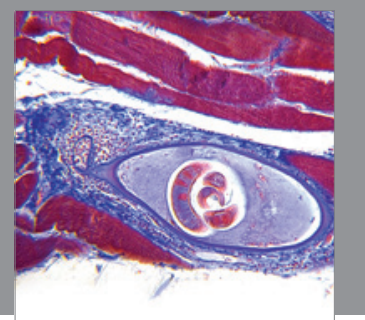

Gastroenterology

Research and Practice
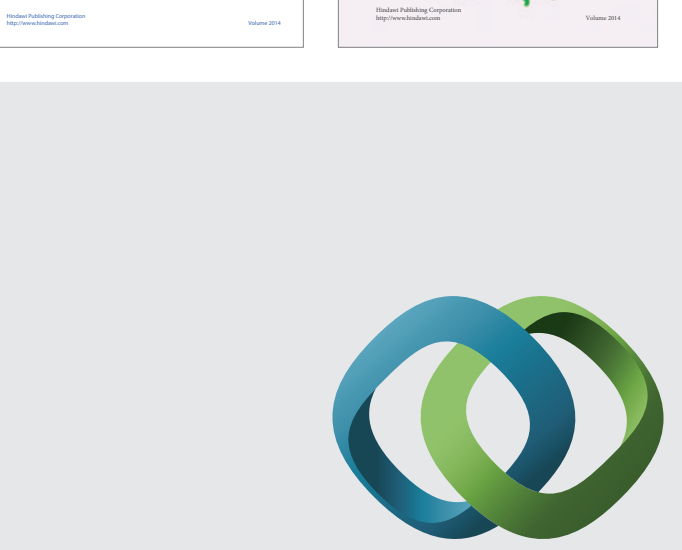

\section{Hindawi}

Submit your manuscripts at

http://www.hindawi.com
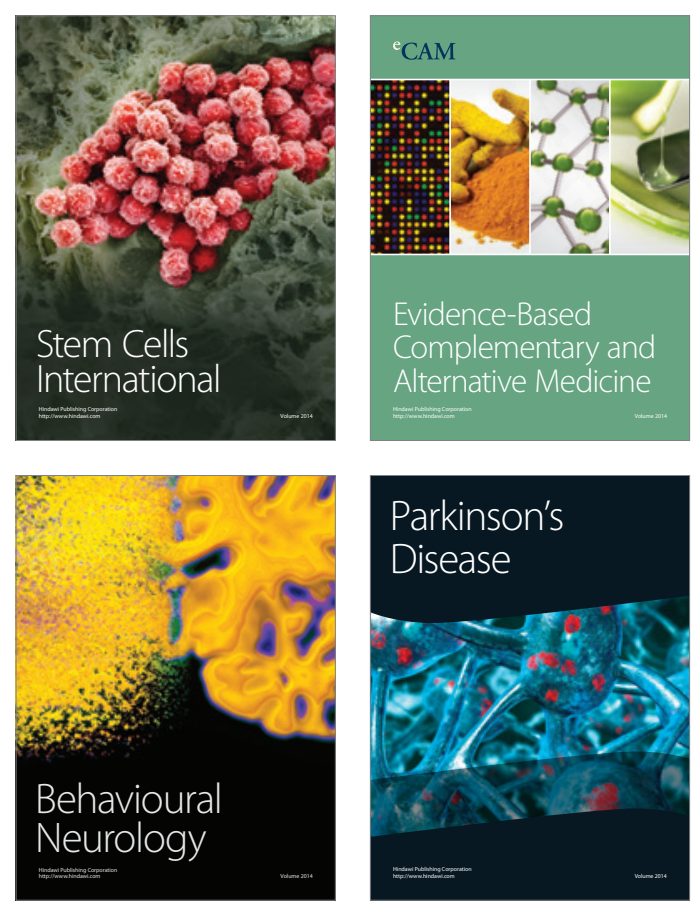

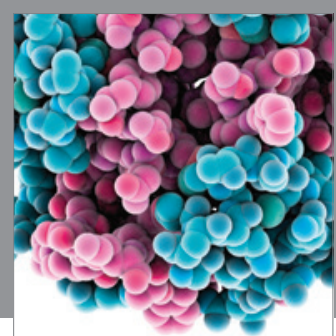

Journal of
Diabetes Research

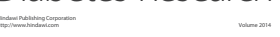

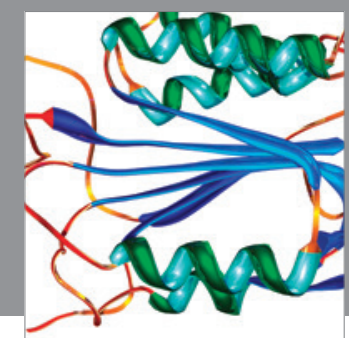

Disease Markers
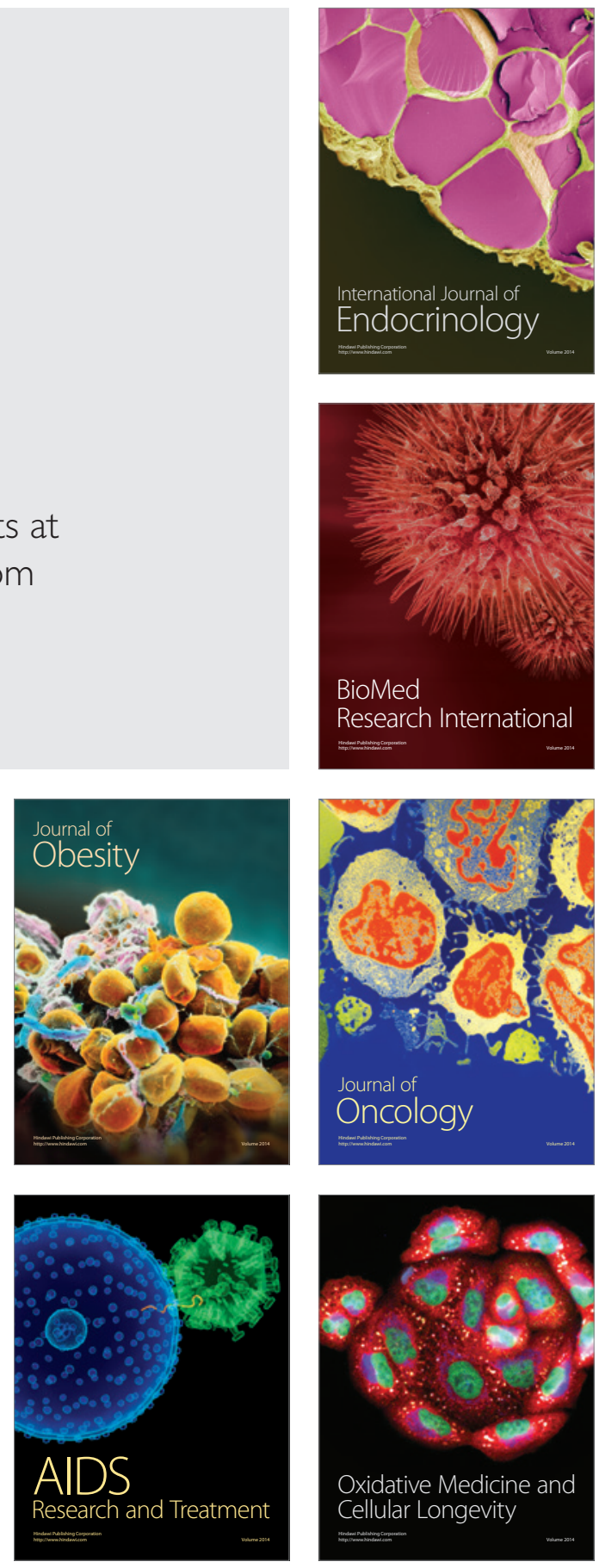